\title{
DOCÊNCIA NA EDUCAÇÃO PROFISSIONAL E TECNOLÓGICA: UMA PROPOSTA DE FORMAÇÃO CONTINUADA NO ÂMBITO DO ESPAÇO ESCOLAR
}

\author{
TEACHING IN EDUCATION PROFESSIONAL AND TECHNOLOGY: A PROPOSAL \\ FOR CONTINUING EDUCATION UNDER THE SCHOOL SPACE
}

\author{
Nísia Maria Teresa Salles ${ }^{1}$, Raquel Almeida $\operatorname{Costa}^{2}$ e Fabiano de Cristo da Fonseca e Salles ${ }^{3}$
}

\begin{abstract}
RESUMO
Este artigo descreve um estudo sobre a importância e as possibilidades de se discutir no âmbito dos Institutos Federais, um programa de formação continuada que contemple as necessidades apresentadas pelos professores no exercício da profissão docente, para visualizar como os docentes que atuam na educação profissional e tecnológica aprendem a ensinar e quais são os saberes necessários ao exercício da docência. Partindo de alguns questionamentos: quais são os saberes que os docentes consideram fundamentais para a sua prática em sala de aula? Como adquirem esses saberes sobre o processo de ensinar? Que saberes subsidiam sua prática pedagógica e se constroem em sua trajetória? Buscam-se por meio da análise bibliográfica de autores alguns resultados que poderão constituir-se em elementos importantes para a compreensão do trabalho docente nos Institutos Federais, no contexto da nova institucionalidade decorrente do atual processo de expansão de Rede Federal de Educação Profissional, Científica e Tecnológica no Brasil.
\end{abstract}

PALAVRAS-CHAVE: Educação Profissional e Tecnológica; Formação Docente; Formação Continuada.

\section{ABSTRACT}

This article describes a study on the importance and possibilities of discussing under the Federal Institutes, a continuing education program that addresses the needs presented by the teachers in the exercise of the teaching profession, to see how teachers working in vocational and technological education they learn to teach and what are the knowledge necessary to carry out teaching. Starting with some questions: What are the knowledge that teachers consider essential to their practice in the classroom? How to acquire this knowledge about the process of teaching? That knowledge subsidize their practice and build on its history? are searched through literature review authors some results that may be in important elements for understanding the teaching work in the Federal Institutes in the context of the new institutional framework resulting from the current process of expanding Federal Professional Education Network, Scientific and technology in Brazil.

KEYWORDS: Professional and Technological Education; Teacher Training; Continuing Education.

\section{INTRODUÇÃO}

Embora nos últimos anos tenham se ampliado as vozes na defesa da capacitação, não se evidenciaram políticas públicas incisivas no sentido de qualificação docente, dificuldade

\footnotetext{
${ }^{1}$ Universidade Federal de Uberlândia - UFU. E-mail: nisia@iftm.edu.br

${ }^{2}$ Universidade Federal de Uberlândia - UFU. E-mail: raquelalmeida@iftm.edu.br

${ }^{3}$ Universidade Presidente Antônio Carlos - UNIPAC. E-mail: fabiano.fonseca.salles@gmail.com
} 
esta que deve e pode ser vencida com esforço, no sentido de um trabalho mais integrado e participativo, que articule a competência técnica ao saber-fazer pedagógico inerente à atividade da docência. $O$ que se tem de concreto é a convicção de que a formação de professores para a educação, e neste insere-se a educação profissional, se traduz em política inadiável e perene, diante do compromisso com a expansão desta modalidade de ensino de forma qualificada, democrática e sintonizada com os ideais de construção de uma nação soberana do ponto de vista social, econômico, cultural e científico. Nesse contexto, a prática cotidiana como espaço de construção de conhecimentos/saberes sobre o ensino, a escola como locus de formação docente, a construção da identidade dos docentes em sua trajetória profissional, são temas que sobressaem.

Observa-se, pois, uma mudança de enfoque nas pesquisas no Brasil, nas quais o professor, como sujeito de sua formação, passa a ser objeto de diferentes estudos. Enfatiza-se como questão central o fato de que o docente é um profissional que mobiliza determinados conhecimentos em sua prática pedagógica, na qual o confronto com situações complexas requer posicionamentos que se apoiam sobre um determinado repertório de conhecimentos produzidos no fazer cotidiano do estar professor. Nesse sentido, os docentes são considerados como pessoas que produzem um saber específico sobre o seu trabalho, a partir do conjunto de conhecimentos oriundos de diferentes espaços de formação e da reflexão sobre sua própria prática. O corpo docente das disciplinas técnicas dos cursos de educação profissional e tecnológica é composto em sua maioria por profissionais com diferentes formações na graduação, buscando competências nos níveis de pós-graduação, com qualificação em cursos de mestrado e doutorado em diversas áreas de conhecimento e trabalham como professores, tendo como base o conhecimento do conteúdo específico de sua formação, contando com pouca ou nenhuma referência pedagógica. Nesse sentido alguns questionamentos norteiam esse estudo, sendo eles: quais são os saberes que os docentes da Educação Profissional e Tecnológica consideram fundamentais para a sua prática em sala de aula? Como adquirem esses saberes sobre o processo de ensinar? Que saberes/conhecimentos subsidiam sua prática pedagógica e são construídos/demandados em sua trajetória profissional? Considerando os estudos e as questões apresentadas, bem como a necessidade de aprofundamento de investigações sobre essa temática, busca-se por meio de uma pesquisa teórico-bibliográfica de autores que estudam essa problemática, compreender como os docentes que atuam na educação profissional e tecnológica aprendem a ensinar e quais são os saberes necessários ao exercício da docência. Os resultados de tais estudos poderão constituir-se em elementos 
importantes para a compreensão do trabalho docente nos Institutos Federais, no contexto da nova institucionalidade decorrente do atual processo de expansão de Rede Federal de Educação Profissional, Científica e Tecnológica no Brasil.

\section{Um Breve Olhar: a Educação Profissional e Tecnológica}

Revisitando a história da educação técnica no Brasil, podemos verificar que, desde sua origem, esta modalidade de ensino preocupou-se com questões democráticas alinhadas aos ideais de uma nação preocupada com questões sociais, tendo em vista que a primeira regulamentação desta educação técnica referia-se ao ensino destinado às "classes menos favorecidas", com a escola de aprendizes de artífices (Brasil, 1937). Entretanto, estes ideais foram deturpados por questões capitalistas e liberalistas, conforme veremos, contradizendo sua própria origem e seus princípios de expansão contemporâneos.

A partir de Julho de 2008, a educação profissional e tecnológica passa a integrar a Lei $\mathrm{n}^{\mathrm{o}}$ 9.394/96, de diretrizes e bases da educação. As alterações na LDB tiveram o propósito de transformar em lei as inovações trazidas pelo Plano de Desenvolvimento da Educação (PDE), objetivando a melhor preparação dos profissionais de nível médio, elevando a escolaridade dos trabalhadores. Os artigos 37, 39, 41 e 42 da Lei de Diretrizes e Bases da Educação Nacional (LDB), propõe que a educação profissional integre-se aos diferentes níveis e modalidades de educação e às dimensões do trabalho, da ciência e da tecnologia. Passam a ser organizados por eixos tecnológicos, possibilitando assim a construção de diversos itinerários formativos com aperfeiçoamento do aluno na área escolhida. A lei também dispõe sobre os tipos de cursos que a educação profissional e tecnológica abrange de formação inicial e continuada ou qualificação profissional, técnica de nível médio e tecnológica de graduação e pós-graduação (BRASIL, 2010).

Na década de 70, o desenvolvimento de uma educação profissionalizante significou uma formação de recursos humanos e uma qualificação acelerada de mão de obra, tendo como pano de fundo a Teoria do Capital Humano: o capital, ao buscar uma formação específica de indivíduo necessária à produção, impõe sua ética, em detrimento da ética social. A educação tornou-se um filtro eficaz para a reprodução da hierarquia da sociedade, um instrumento capaz de promover, sem qualquer resistência, a força de trabalho necessária ao desenvolvimento econômico; nesta medida, assegurou a produção e a distribuição do poder na 
organização social, apesar de sua forma fragmentada. Através do modo de produção no capitalismo surge a dominação do capital sob a exploração do trabalho, onde o sistema econômico assume uma postura contraditória e conflitante, que o impede, enquanto modelo determinante de sociedade, de romper com as relações sociais de exclusão e de socializar o resultado do trabalho, isto é, de distribuir igualmente o resultado do trabalho a todo o coletivo. Nos anos 80, sugere-se o desenvolvimento econômico sustentado, cujo crescimento econômico se vincula ao desenvolvimento social. A atuação do Governo, na área das políticas sociais, era de cunho puramente compensatório, e, neste sentido, a educação foi concebida como possibilidade concreta de melhoria de vida para a camada assalariada do setor produtivo. O Ensino Técnico teve suas funções especificadas pelo processo de desenvolvimento sustentado com equidade social, estruturando-se a partir da prescrição de sua atuação em três níveis: industrial, desenvolvimento tecnológico e o social, sendo estes destinados à qualificação da mão de obra demandada pelos mercados de trabalho, conforme suas especificidades técnicas, além de desenvolver, adaptar e assistir as indústrias no uso de tecnologia, com a sua tarefa voltada para o social estabelecida pela meta de promover a valorização do técnico através da qualidade de seu processo de formação e da inserção de seus egressos no mercado, como técnico. O Ensino Técnico da década de 90 vem se estabelecendo, pois, a partir da estruturação da lógica capitalista como modelo de organização da sociedade.

Esta (re)estruturação veio sendo elaborada com base na vertente liberal do capitalismo, na qual, as esferas sociais, políticas e econômicas são determinadas pelas regras mercantis. Assim, as relações sociais e a estrutura de governo são planejadas sob uma premissa de desenvolvimento que está vinculada às premissas de relações e valor de mercado, os quais se apresentam como padrões dominantes de visão de mundo, visto que o propósito de consolidação da estabilidade econômica do país se faz por meio da imagem do Estado limitado pela privatização dos seus recursos estatais e pela comercialização privada da esfera pública. Todas as medidas adotadas neste período foram acompanhadas por implantação de políticas neoliberais evidenciadas no governo Fernando Henrique Cardoso, através da aprovação do Plano Diretor da Reforma do Aparelho do Estado, elaborado por Bresser Pereira, em 1995, então titular do Ministério da Administração Federal e da Reforma do Estado que propõe a estratégia de retração do Estado, ampliando espaços para as relações com o mercado, em detrimento de interesses públicos e dos direitos sociais da maioria dos cidadãos (BRASIL, 1995). As diretrizes nacionais para o Ensino Técnico lançadas na reforma 
do Ensino Técnico de 1996 generalizam a ideia de educação de qualidade que se traduz em um propósito de preparação do jovem para um aprendizado permanente, contextualizado em relação às exigências sociais apresentadas de acordo com a necessidade de alcance do desenvolvimento do país, vinculado à rede de reestruturação do trabalho no capitalismo cada vez mais realçado pelas políticas neoliberais (BRASIL, 1996c).

Os novos rumos da educação profissional no Brasil, marcada por novas políticas de gestão da educação profissional, abrem caminhos que nos levam à investigação dos fatores históricos, para entendimento dos rumos futuros da educação como um todo, traçando-se os parâmetros que nos levam a uma educação técnica voltada para a geração de mão de obra qualificada, em virtude do desenvolvimento da nação, que implicam no estudo sistematizado das políticas do mercado de trabalho que nos proporciona uma hipótese de trabalho não só de levantamento de dados históricos, mas também de uma perspectiva real do processo de formação dos Institutos Federais como base da formação profissional do país. Estes aspectos notórios na política educacional do Brasil deste novo século, estabelecem uma visão diferenciada das políticas de formação docente e suas práticas, levando-nos a uma reflexão constante que diferencia o saber e o fazer na e para a educação, buscando esclarecer as funções e finalidades dos Institutos Federais, bem como sua inserção numa sociedade capitalista em constante transformação, gerando também a necessidade de repensar a formação e a prática educativa do professor que se transforma no pilar de sustentação de sua práxis, envolvendo também o relacionamento entre trabalho e educação, constantemente questionado a partir do campo de atuação dos profissionais de educação em seus mais amplos aspectos.

\section{O Docente nos Institutos Federais - Uma Construção Histórica}

No percurso histórico inserido à globalização, a docência e o processo de formação docente, e consequentemente o processo de formação continuada, constitui-se como importante objeto de investigação em pesquisas educacionais. Por ser um processo complexo, que se permeia por uma longa trajetória, este movimento integra e articula as dimensões sociais, políticas, filosóficas e culturais da educação.

O processo de profissionalização docente sempre esteve estreitamente vinculado aos impasses e desafios enfrentados pela história da educação. $\mathrm{O}$ advento da industrialização e 
aplicação de conceitos taylorista-fordista no mundo do trabalho refletiu na estrutura e organização da escola. Esse modelo de organização empresarial impactou a profissão docente na medida em que suprimiu grande parte da função do professor de agir e pensar sobre o processo pedagógico, transferindo-o para os especialistas. A verticalização das orientações oficiais no que concerne à apresentação de reformas e propostas pedagógicas vem desconhecendo o direito do professor de discutir políticas que seriam incumbência da função docente. Somando-se a tudo isso um crescente processo de valorização/desvalorização da profissão docente, a discussão acerca de sua formação permanece em pleno debate.

Atualmente, com a globalização neoliberal, um novo paradigma representado pela reestruturação produtiva ${ }^{4}$, em detrimento das inovações tecnológicas, foi introduzido no mundo do trabalho ${ }^{5}$. A educação, neste cenário, constitui um veículo democrático de acesso à cultura, à informação e ao desenvolvimento humano. Assim, a formação e profissionalização docente emerge como um tema de relevância na atualidade sendo palco de debates constituindo-se eixos de estudos, pesquisas e políticas públicas. A garantia de um exercício profissional de qualidade consubstancia-se na ideia de profissionalização docente condicionada à formação inicial e continuada. Tais condições sopesam aspectos como aprendizagem e desenvolvimento de competências, habilidades e atitudes profissionais; salários compatíveis com a natureza e exigência do trabalho docente; condições de trabalho digno, dentre outros.

Ser um profissional da educação implica, desta forma, o domínio de um conjunto de saberes, competências e habilidades específicas que o capacita para o exercício da docência, assegurando também um pertencimento a um grupo profissional organizado sujeito a controle, como afirma Imbernón (2006). Nessa perspectiva, Tardif (2002) propõe que os professores sejam sujeitos do conhecimento, haja vista a mobilização, utilização, produção, significação e resignificação de saberes específicos na prática cotidiana da sala de aula.

\footnotetext{
${ }^{4}$ De acordo com Garay, reestruturação produtiva é "o termo que engloba o grande processo de mudanças ocorridas nas empresas e principalmente na organização do trabalho industrial nos últimos tempos, via introdução de inovações tanto tecnológicas como organizacionais e de gestão, buscando-se alcançar uma organização do trabalho integrada e flexível" (GARAY, 1997).

${ }^{5}$ Nas palavras de Figaro, mundo do trabalho é "o conjunto de fatores que engloba e coloca em relação à atividade humana de trabalho, o meio ambiente em que se dá a atividade, as prescrições e as normas que regulam tais relações, os produtos delas advindos, os discursos que são intercambiados nesse processo, as técnicas e as tecnologias que facilitam e dão base para que a atividade humana de trabalho se desenvolva, as culturas, as identidades, as subjetividades e as relações de comunicação constituídas nesse processo dialético e dinâmico da atividade" (FIGARO, 2008, p.92).
} 
Aqui, inserem-se os Institutos Federais de Educação, Ciência e Tecnologia (doravante, Institutos Federais), criados pelo governo federal, através do Ministério da Educação (MEC), com o propósito de ser um modelo institucional absolutamente inovador em termos de proposta político-pedagógica. De acordo com a Lei $\mathrm{n}^{\mathbf{0}} 11.892$, de 29 de dezembro de 2008, Art. $2^{\circ}$, os Institutos Federais são,

[...] instituições de educação superior, básica e profissional, pluricurriculares e multicampi, especializados na oferta de educação profissional e tecnológica nas diferentes modalidades de ensino, com base na conjugação de conhecimentos técnicos e tecnológicos com as suas práticas pedagógicas, nos termos desta Lei (BRASIL, Art. $2^{\circ}$, Lei $\mathrm{n}^{\mathrm{o}} 11.892$, de 29 de dezembro de 2008) ${ }^{6}$.

Vidor et al. (2011, p. 49- 50), ressalta ainda que “[o] foco dos Institutos Federais é a promoção da justiça social, da equidade, do desenvolvimento sustentável com vistas à inclusão social, bem como a busca de soluções técnicas e a geração de novas tecnologias.". Desde o inicio do governo Lula, o governo federal tem implantado políticas para a ampliação do acesso à educação para milhões de jovens e adultos da classe trabalhadora e para sua permanência nos diversos sistemas de ensino.

A criação dos Institutos Federais se concretizou em 2008 e caracterizou-se como a institucionalização definitiva da Educação Profissional e Tecnológica, como política pública que tem o compromisso de estabelecer igualdade na diversidade (social, econômica, geográfica, cultural, etc.). Assim, a implantação dos Institutos Federais tem o objetivo de desenvolver uma educação profissional cidadã que alcance diferentes grupos e espaços sociais, promovendo o desenvolvimento local e regional. Segundo Pacheco (2011, p.11), o objetivo central dos Institutos Federais [...] "não é formar um profissional para o mercado, mas sim um cidadão para o mundo do trabalho - um cidadão que tanto poderia ser um técnico quanto um filósofo, um escritor ou tudo isso".

A organização pedagógica dos Institutos Federais visa à verticalização do ensino, que vai desde a educação básica até o ensino superior, permitindo aos docentes atuar em todos os níveis de ensino num espaço ímpar de construção de saberes. Aos discentes é dada a oportunidade para que se construam como sujeitos autônomos, pois têm a oportunidade de compartilhar espaços de aprendizagem diversificados delineando sua trajetória de formação

\footnotetext{
${ }^{6}$ Disponível em: <http: //www.planalto.gov.br/ccivil 03/ ato2007.../2008/lei/111892.htm>. Acesso em 15/06/2015.
} 
do curso técnico de nível médio até o doutorado. Os Institutos Federais enfatizam também a indissociabilidade do ensino, da pesquisa e da extensão.

Segundo Pacheco (2011, p.25), a verticalização implica,

[...] o reconhecimento de fluxos que permitam a construção de itinerários de formação entre os diferentes cursos da educação profissional e tecnológica: qualificação profissional, técnica, graduação e pós-graduação tecnológica. A transversalidade auxilia a verticalização curricular ao tomar as dimensões do trabalho, da cultura, da ciência e da tecnologia como vetores na escolha e na organização dos conteúdos, dos métodos, enfim, da ação pedagógica.

Com a expansão e a interiorização da Rede Federal de Educação Profissional e Tecnológica, principalmente a partir de 2008, houve a necessidade de contratação de professores e técnicos administrativos Conforme a portaria interministerial, datada de $10 \mathrm{de}$ junho de 2011, do Ministério do Planejamento, Orçamento e Gestão, referente à última fase de expansão desta rede, de 2011 a 2014, previa-se a contratação de 3.315 professores no âmbito do Ministério da Educação, para atender tanto às demandas dos Institutos Federais, quanto dos Centros Federais de Educação Tecnológica (CEFET-RJ) e de Minas Gerais (CEFET-MG), e do Colégio Pedro II, todas estas instituições de educação profissional e tecnológica. Apesar dos claros intuitos de expansão previstos nas políticas públicas, estas mesmas políticas, no que tange à qualidade formativa destes profissionais que atuam nesta educação, estão aquém e dissonantes desta expansão.

Inseridos neste contexto, os Institutos Federais estão em processo de construção de sua identidade no que se refere aos profissionais responsáveis por esta modalidade de educação, o que gera inúmeros questionamentos, debates e reflexões. É nesse cenário que surgem inquietações com relação à formação didático-pedagógica dos docentes para o exercício do magistério superior. Por esta razão, a presente proposta permeia as discussões sobre os processos de desenvolvimento da identidade profissional dos docentes que atuam na educação tecnológica dos Institutos Federais. Mesmo não sendo um tema novo nas pesquisas sobre formação de professores, no campo da educação superior, existe uma carência em pesquisas relativas a essa abordagem, no que concerne especificamente aos recém-criados Institutos Federais.

Longe de encontrar respostas, este estudo teórico-bibliográfico visa a investigação dos fatores envolvidos no processo de socialização profissional do professor destas unidades de ensino, pautando-se na identificação do processo de profissionalização e desenvolvimento 
da identidade profissional, ressaltando as dificuldades e necessidades formativas encontradas no exercício da docência, inserindo-se na prática social, com papel fundamental na formação humana.

Sabemos que esta formação constrói-se a partir da autonomia e conhecimento especializado, manifestado em competência e capacidade para desempenhar o trabalho com compromisso, responsabilidade, profissionalismo. Assim, o estudo sistemático de aspectos sublimados na profissionalização é importante para a avaliação do campo social, uma vez que a realização destes estudos permite conferir o alcance da formação e dos saberes docentes na constituição desta profissionalização. André (2011, p. 27) afirma ainda que:

Um indicador adicional de constituição da área é a insistente atenção dos políticos, administradores e investigadores à formação dos professores como peça-chave da qualidade do sistema educativo. Esse talvez seja o aspecto mais visível de configuração da área no Brasil, pois temos ouvido frequentes depoimentos de políticos e visto inúmeras matérias em jornais e revistas que enfatizam o papel crucial da formação docente na melhoria da educação brasileira.

É preciso ainda ressaltar que a profissionalização docente é um campo da educação como prática social, e, portanto traz consigo uma multiplicidade de questões e embates que à luz de uma investigação concorrem para o avanço e a consolidação dessa área de conhecimento.

\section{Profissão Docente, Profissionalização Docente - Novos Rumos, Novos Olhares}

Segundo Marcelo (2009), o desenvolvimento profissional docente deve ser visto como um processo, individual e ou coletivo que se contextualiza a partir do seu local de trabalho, sendo que este contribui para o desenvolvimento de suas competências a partir de suas experiências formais e informais. Este conceito modifica-se ao longo do tempo do mesmo modo que se constituem o desenvolvimento dos processos de ensino e aprendizagem, visto que este decorre de um longo prazo, integrando não só as oportunidades, mas também as experiências que advém das novas perspectivas de desenvolvimento e dos debates acerca do processo de profissionalização.

Ainda assim, apesar de rodeada de discussões e paradigmas, a docência pode ser vista como um campo em que há muito por se fazer. Com o avanço da sociedade rumo à ciência e 
tecnologia, o conhecimento tem papel de destaque, e o grande desafio da educação é incorporar as mudanças exigidas por esta sociedade. Estas exigências criam novas demandas com relação às exigências de formação do professor.

Mas há que se pensar sobre estas exigências, conforme aponta Nóvoa (2008), quando posiciona que há a necessidade de adaptação destas necessidades, para que estas ultrapassem a mera reprodução dos discursos. Retoma-se a necessidade de políticas que reforcem a profissão docente, valorizando seus saberes e campos de atuação, que valorizem também as suas culturas, não generalizando apenas a profissão enquanto função social deixando de lado a retórica do discurso, mas dando sentido de autonomia em sua construção profisssional, em especial neste novo século.

Tardif (2000, p. 8) complementa que:

Desse ponto de vista, em educação, a profissionalização pode ser definida, em grande parte, como uma tentativa de reformular e renovar os fundamentos epistemológicos do ofício de professor e de educador, assim como da formação para

o magistério.

Não há como ignorar estes novos conceitos que surgem à margem da educação, em especial na formação do profissional docente dos Institutos Federais que, ainda desprovido de uma identidade certa, assim como os docentes dos mais diversos níveis de ensino, se pauta no mérito de sua formação, cujo objetivo permeia a formação de um cidadão autônomo, investigativo, crítico, reflexivo e criativo, onde os conhecimentos específicos superam a dicotomia teoria e prática no atendimento ao mundo do trabalho. Seu papel de formador direciona esta diversidade contextualizada de seu papel profissional, que ainda está no centro de toda discussão acerca da identidade do professor. A complexa caracterização de uma formação continuada perpassa pela diversidades de objetivos, interesses e agentes envolvidos, lembrando-se ainda da riqueza de informações, que torna inviável o pensamento de algo desnecessário. Entretanto, muitas ações se acham elencadas no processo de profissionalização docente e que não se restringem apenas às ações que possam auxiliar o professor em seu desempenho profissional, restringindo sua profissionalização a cursos formalizados e estruturados que se oferecem após o ingresso no magistério e sendo utilizados genericamente enquanto profissionalização docente. 


\section{Em Busca de Conclusões - A Formação da Identidade do Professor dos Institutos Federais}

Sem a pretensão de concluir que os desafios da profissão docente possa dar conta de todas as suas dificuldades, a intenção é que esta análise da identidade do Professor que constitui hoje os Institutos Federais estabeleça relações entre o exercício de reflexão sobre a prática docente, que aponte os desafios da construção do conhecimento profissional visto que uma das características da educação é possibilitar o contato com experiências e reflexões que nos levem à compreensão e a busca de soluções de problemas que se enfrenta no cotidiano da prática profissional, que decorre dos desafios postos pela educação contemporânea, que reflita diretamente nos desafios que a educação enfrenta de maneira generalizada. Neste sentido, "ser professor" vai além do domínio científico pois este se configura como produtor e organizador do conhecimento num processo contínuo de aprendizagem, levando este agente a buscar o "tornar-se professor", dominando o ensinar para ativar o interesse do aluno em querer aprender.

As relações conflituosas que surgem na carreira docente da educação profissional e tecnológica requerem da educação sua caracterização enquanto espaço de formação que propicie uma reflexão sobre a prática e a valorização deste profissional. A necessidade de uma profissionalização vista sob a ótica da formação de novos saberes e competências que orientam esta nova visão da construção de uma identidade profissional, que se vincula a um parâmetro democrático da profissão docente, caracterizando assim o espaço escolar enquanto ambiente de formação que constitui o privilégio deste ato, repercutindo significativamente nas práticas dos professores que se veem engajados nestas mudanças, buscando alternativas aos problemas e propondo uma reflexão contínua sobre sua prática e valorização profissional. 


\section{REFERÊNCIAS}

ANDRÉ, Marli. Pesquisas sobre Formação de Professores: tensões e perspectivas do campo. In: Formação de Professores, Culturas: desafios à Pós-graduação em Educação em suas múltiplas dimensões/ Helena Amaral da Fontoura e Marco Silva (orgs.). Rio de Janeiro: ANPEd Nacional, 2011.

BOGDAN, Robert; BIKLEN, Sari Kopp. Investigação qualitativa em educação: uma introdução à teoria e os métodos. Tradução Maria João Alvarez, Sara Bahia dos Santos e Telmo Mourinho Baptista. Portugal: Porto, 1994.

BRASIL. Constituição (1937). Constituição da República dos Estados Unidos do Brasil. Rio de Janeiro. RJ: 1937. Disponível em <http://www2.camara.leg.br/legin/fed/consti/19301939/constituicao-35093-10-novembro-1937-532849-publicacaooriginal-15246-pe.html>. Acesso em $18 / 06 / 15$.

Plano Diretor da Reforma do Aparelho do Estado - PDRAE. Brasília: Ministério da Administração Federal e Reforma do Estado. Brasília, DF: 1995. Disponível em < http://www.bresserpereira.org.br/documents/mare/planodiretor/planodiretor.pdf $>$. Acesso em $11 / 07 / 2015$

. Ministério do Planejamento, Orçamento e Gestão. Portaria Interministerial no 149 de 10 de junho de 2011. Publicada no Diário Oficial da União, Seção I, Segunda-feira, 13 de junho de 2011. Brasília, DF: 2011. Disponível em $<$ https://conlegis.planejamento.gov.br/conlegis/redirectDownload.htm?id=8517>. $\quad$ Acesso em $11 / 07 / 2015$.

Lei n. ${ }^{\circ}$ 11.892, de 29 de dezembro de 2008. Institui a Rede Federal de Educação Profissional, Científica e Tecnológica, cria os Institutos Federais de Educação, Ciência e Tecnologia. Brasília. Ministério da Educação, 2008. Disponível em: $<$ http://www.planalto.gov.br/ccivil 03/ ato2007.../2008/lei/111892.htm>. Acesso em 15/ 06/2015.

MEC/Setec. Concepção e diretrizes - Instituto Federal de Educação, Ciência e Tecnologia. Brasília: MEC/Setec, 2008a.

Lei n. ${ }^{\circ}$ 9.394, de 20 de dezembro 1996 - 5a Edição Atualizada. Estabelece as diretrizes e bases da educação nacional. Disponível em:. Brasília: Edições Câmara, Centro de Documentação e Informação, 2010, acesso em 23/06/2015.

FIGARO, Roseli. O mundo do trabalho e as organizações: abordagens discursivas de diferentes significados. Revista ORGANICOM, p. 90-100. Ano 5-número 9-2º semestre de 2008.

GARAY, A. B. S. Reestruturação produtiva e desafios de qualificação: algumas considerações críticas. READ - Revista Eletrônica da Administração (UFRGS). Porto Alegre, v.3, n.1,1997.

IMBERNÓN, F. Formação docente e profissional: formar-se para a mudança e a incerteza. São Paulo: Cortez, 2006.

MARCELO, Carlos. Desenvolvimento Profissional Docente: passado e futuro. Sísifo. N. 08. 2009. p. $7-22$.

MARTINS, Gilberto de Andrade. Manual para elaboração de monografias e dissertações. 2 ed. São Paulo : Atlas, 2000. 
NÓVOA, Antônio (Org). Professores e sua formação. Lisboa, Dom Quixote, 1992.

O regresso dos professores. Conferência Desenvolvimento Profissional de Professores para a Qualidade e para a Equidade da Aprendizagem ao longo da Vida. 2008. Anais. p. 21-28.

PACHECO, Eliezer (org.). Cidadãos para o Mundo do Trabalho. Os Institutos Federais: Uma revolução na Educação Profissional e Tecnológica. Ed. Moderna, Brasília, 2011.

Práticas pedagógicas, profissão docente e formação: perspectivas sociológicas. Lisboa: Dom Quixote, 1997.

PIMENTA, Selma Garrido; ANASTASIOU, Léa das Graças Camargos. Docência no ensino superior. Coleção docência em formação-vol.I. São Paulo: Cortez, 2002.

TARDIF, Maurice; RAYMOND, Danielle. Saberes, tempo e aprendizagem do trabalho do magistério. Educação \& Sociedade, Campinas, v.21, nº73, p.209-244, 2000.

. Saberes docentes e formação profissional. Petrópolis: Vozes, 2002.

Saberes Profissionais dos Professores e conhecimentos universitários. In: Revista Brasileira de Educação. São Paulo, n. 13, p. 03-24. Jan./abr 2000.

VIDOR, Alexandre et al. Institutos Federais: antecedentes. In: PACHECO, Eliezer (org.). Os Institutos Federais: Uma revolução na Educação Profissional e Tecnológica. Ed. Moderna, Brasília, 2011.

RECEBIDO EM: 02/03/2016

APROVADO PARA PUBLICAÇÃO EM: 29/11/2016 